06

\title{
Синтез графена методом холодной имплантации атомов отдачи углерода
}

\author{
(С) Ю.А. Агафонов ${ }^{1}$, В.И. Зиненко ${ }^{1,}$, О.В. Кононенко ${ }^{1}$, \\ B.B. Сарайкин ${ }^{2}$ \\ ${ }^{1}$ Институт проблем технологии микроэлектроники и особочистых \\ материалов РАН, Московская область, Черноголовка \\ ${ }^{2}$ Научно-исследовательский институт фризических проблем \\ им. Ф.В. Лукина, Москва, Зеленоград \\ ฯ E-mail: zinenko@iptm.ru
}

Поступило в Редакцию 8 февраля 2017 г.

Предложен новый способ введения углерода в металлические каталитические пленки для синтеза графена. Способ основан на явлении имплантации атомов отдачи углерода из слоя молекул метана, адсорбированных на металлической пленке, при облучении такой структуры ионами инертных газов. Для увеличения толщины адсорбированного слоя метана образцы охлаждались до температуры $-190^{\circ} \mathrm{C}$. Этот метод был реализован на поликристаллической пленке никеля. После отжига на поверхности никелевой пленки методом рамановской спектроскопии обнаружены многочисленные фрагменты многослойного графена.

DOI: 10.21883/PJTF.2017.12.44708.16736

Одним из ключевых вопросов в большинстве методов синтеза графена является способ строго дозированной доставки атомов углерода на поверхность или в объем каталитических подложек (в основном металлов $\mathrm{Ni}, \mathrm{Co}, \mathrm{Fe}, \mathrm{Ru}, \mathrm{Cu}$ ), на которых выращиваются пленки графена. В этом плане введение атомов углерода методом ионной имплантации является уникальным по своей прецизионности. Варьируя дозу имплантации, можно управлять количеством монослоев синтезируемого графена. Однако практически во всех работах, связанных с синтезом пленок графена методом ионной имплантации, отмечается, что количество углерода, определенное в имплантированных металлических пленках, всегда превышает дозу ионной имплантации [1-3]. Авторы связывают это с загрязнением углеродом металлических пленок при их выращивании, а также в процессе различных анализов и 
отжига, проводимых после имплантации. Но есть еще один источник загрязнения углеродом при ионной имплантации, на который никто не обращает внимания. Это имплантация атомов отдачи углерода из слоя углеродсодержащих молекул остаточных газов, адсорбированных на поверхности металлической пленки при имплантации первичного пучка ионов углерода. Это явление наблюдалось нами ранее при имплантации ионов бора в кремний [4]. Предельный рабочий вакуум в имплантере определяется молекулярным потоком рабочего газа, на котором работает ионный источник (в случае получения ионов углерода в основном используется газ $\mathrm{CO}_{2}$ ). Согласно кинетической теории газов, даже при парциальном давлении $\mathrm{CO}_{2}$ в камере имплантера $\sim 1.3 \cdot 10^{-4} \mathrm{~Pa}$ поток молекул $\mathrm{CO}_{2}$ на образец составляет $\sim 3 \cdot 10^{14} \mathrm{~mol} / \mathrm{cm}^{2} \cdot \mathrm{s}$. Этот поток на 1.5 порядка величины больше плотностей тока пучка ионов углерода (обычно микроамперного диапазона), используемых в экспериментах по синтезу пленок графена $\left(1 \mu \mathrm{A} / \mathrm{cm}^{2}\right.$ соответствует потоку $\left.6.25 \cdot 10^{12} \mathrm{ion} / \mathrm{cm}^{2} \cdot \mathrm{s}\right)$. Таким образом, на поверхности металлической пленки постоянно присутствует слой из молекул $\mathrm{CO}_{2}$, степень покрытия поверхности которыми, а значит и количество атомов отдачи углерода, внедряемых в металлическую пленку, будет зависеть от парциального давления $\mathrm{CO}_{2}$ в камере имплантера, дозы и энергии ионов углерода.

Проявление эффекта имплантации атомов отдачи углерода из адсорбированных на поверхности никеля слоев углеродсодержащих молекул хорошо видно на рис. 1, $a$, где приведен профиль распределения атомов углерода в пленке никеля, имплантированного ионами углерода с энергией $70 \mathrm{keV}$ и дозой $1 \cdot 10^{16} \mathrm{~cm}^{-2}$. Профиль снят методом вторичной ионной масс-спектрометрии (ВИМС). Наряду с основным имплантационным профилем (максимум распределения при $\sim 65 \mathrm{~nm}$ ) наблюдается узкий приповерхностный пик атомов углерода, простирающийся от поверхности до глубины $\sim 20 \mathrm{~nm}$. Суммарная эквивалентная доза атомов углерода (площадь под всем профилем) составляет $1.25 \cdot 10^{16} \mathrm{~cm}^{-2}$. Таким образом, на приповерхностный пик атомов отдачи углерода приходится $\sim 20 \%\left(2.5 \cdot 10^{15} \mathrm{~cm}^{-2}\right)$ от суммарной внедренной дозы, эта величина близка к поверхностной плотности однослойной пленки графена $\left(3.8 \cdot 10^{15} \mathrm{~cm}^{-2}\right)$. Отметим, что калибровка атомной концентрации углерода проводилась по известной дозе имплантации $\left(1 \cdot 10^{16} \mathrm{~cm}^{-2}\right)$. Однако имеется некоторая неопределенность в величине концентрации в приповерхностной области из-за матричного эффекта метода ВИМС.

Письма в ЖТФ, 2017, том 43, вып. 12 

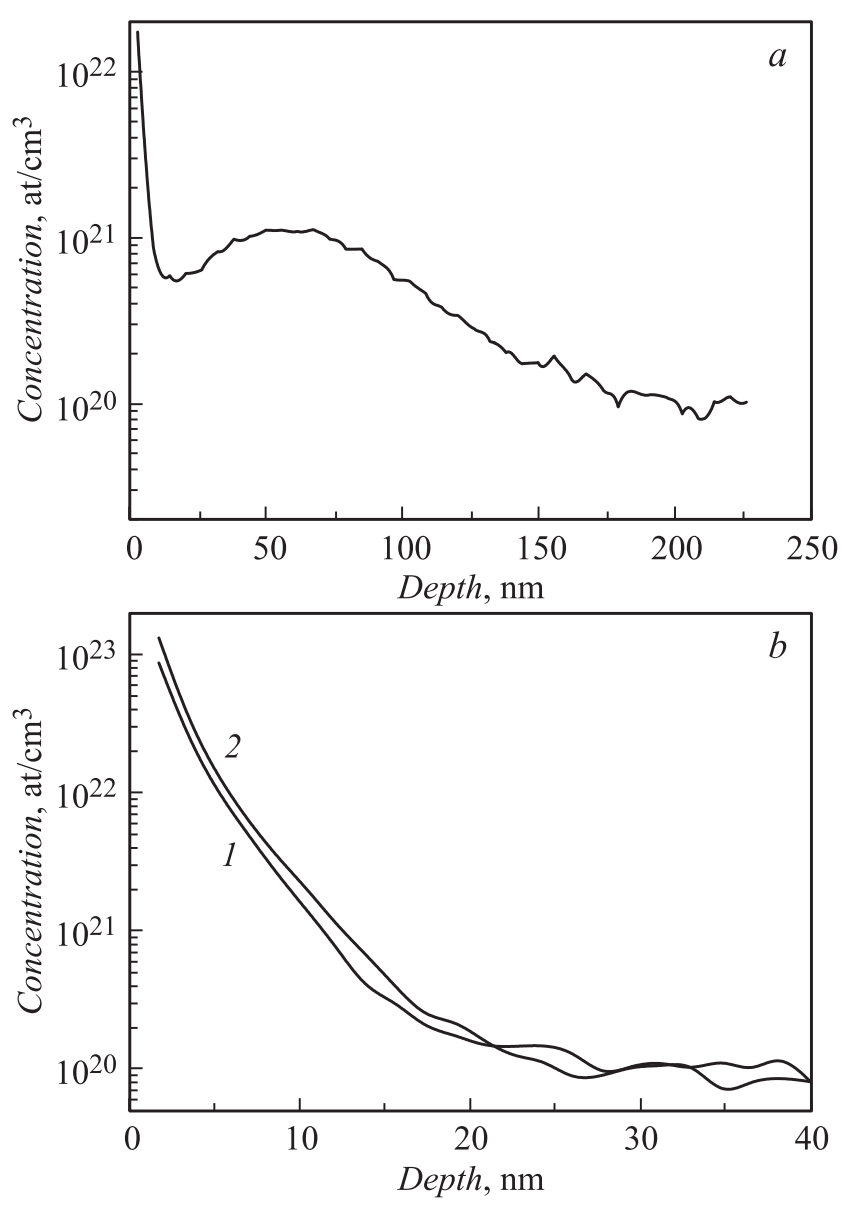

Рис. 1. Профили распределения углерода в никеле: $a-$ после имплантации ионов углерода с энергией $70 \mathrm{keV}$ и дозой $1 \cdot 10^{16} \mathrm{~cm}^{2}, b-$ после холодной имплантации атомов отдачи углерода для доз ионов неона $5 \cdot 10^{14} \mathrm{~cm}^{2}(1)$ и $1 \cdot 10^{15} \mathrm{~cm}^{2}(2)$.

Мы попытались использовать явление имплантации атомов отдачи углерода для синтеза пленок графена на никеле. Преимущество этого метода по сравнению с традиционным методом имплантации ионов

Письма в ЖТФ, 2017, том 43, вып. 12 
углерода на большую глубину очевидно, если вместо первичного пучка использовать ионы инертных газов, а для создания на никеле адсорбированного слоя использовать напуск в камеру образцов углеродсодержащих газов, например метана $\left(\mathrm{CH}_{4}\right)$, ацетилена $\left(\mathrm{C}_{2} \mathrm{H}_{2}\right)$. В этом случае будем иметь единственный источник поступления углерода в никелевую пленку. Более радикальным способом увеличения толщины адсорбированного слоя молекул метана может быть понижение температуры пленки никеля. Если образец охладить до температуры ниже температуры плавления углеродсодержащего газа, то можно получить адсорбированный слой в твердой фазе [5]. Еще одним положительным фактором такого метода является то, что внедренные атомы углерода сосредоточены в тонком приповерхностном слое. Это будет способствовать быстрому выходу углерода на поверхность никелевой пленки при отжиге для синтеза графена и уменьшит время отжига.

В качестве подложки для синтеза пленок графена использовались пленки никеля, напыленные на окисленный кремний методом частично ионизованного потока [6]. Для напыления использовался никель высокой чистоты (99.999 at.\%). Толщина пленки никеля составляла $0.4 \mu \mathrm{m}$. После отжига образцов в вакууме $\left(15 \mathrm{~min}, 1000^{\circ} \mathrm{C}\right)$ на поверхности никеля наблюдалась зернистая структура с размером зерен до 5-15 $\mu \mathrm{m}$. Образцы крепились на держателе в вакуумной камере имплантера EXTRION 200-1000 (фирма Varian). Конструкция держателя позволяла охлаждать образцы до низких температур с использованием жидкого азота. Камера откачивалась до давления $1 \cdot 10^{-4} \mathrm{~Pa}$, затем образцы охлаждались до температуры $\sim-190^{\circ} \mathrm{C}$ и устанавливалось натекание метана на уровне его парциального давления $\sim 3.4 \cdot 10^{-4} \mathrm{~Pa}$. В этом режиме образцы были облучены двумя дозами ионов неона: $5 \cdot 10^{14}$ и $1 \cdot 10^{15} \mathrm{~cm}^{-2}$ с энергией $40 \mathrm{keV}$.

На рис. $1, b$ приведен ВИМС-профиль распределения атомов отдачи углерода в пленке никеля для дозы $5 \cdot 10^{14} \mathrm{~cm}^{-2}$. Внедренные атомы отдачи углерода сосредоточены в тонком приповерхностном слое толщиной $\sim 20 \mathrm{~nm}$. Площадь под профилем распределения (эквивалентная доза внедренного углерода) в 5 раз превышает площадь под приповерхностным пиком углерода при классической имплантации (рис. $1, a)$, что говорит об эффективности метода. Увеличение дозы ионов неона в 2 раза $\left(1.0 \cdot 10^{15} \mathrm{~cm}^{-2}\right)$ увеличивает эквивалентную дозу внедренных атомов углерода всего лишь на $30 \%$. Это свидетельствует об умень-

Письма в ЖТФ, 2017, том 43, вып. 12 

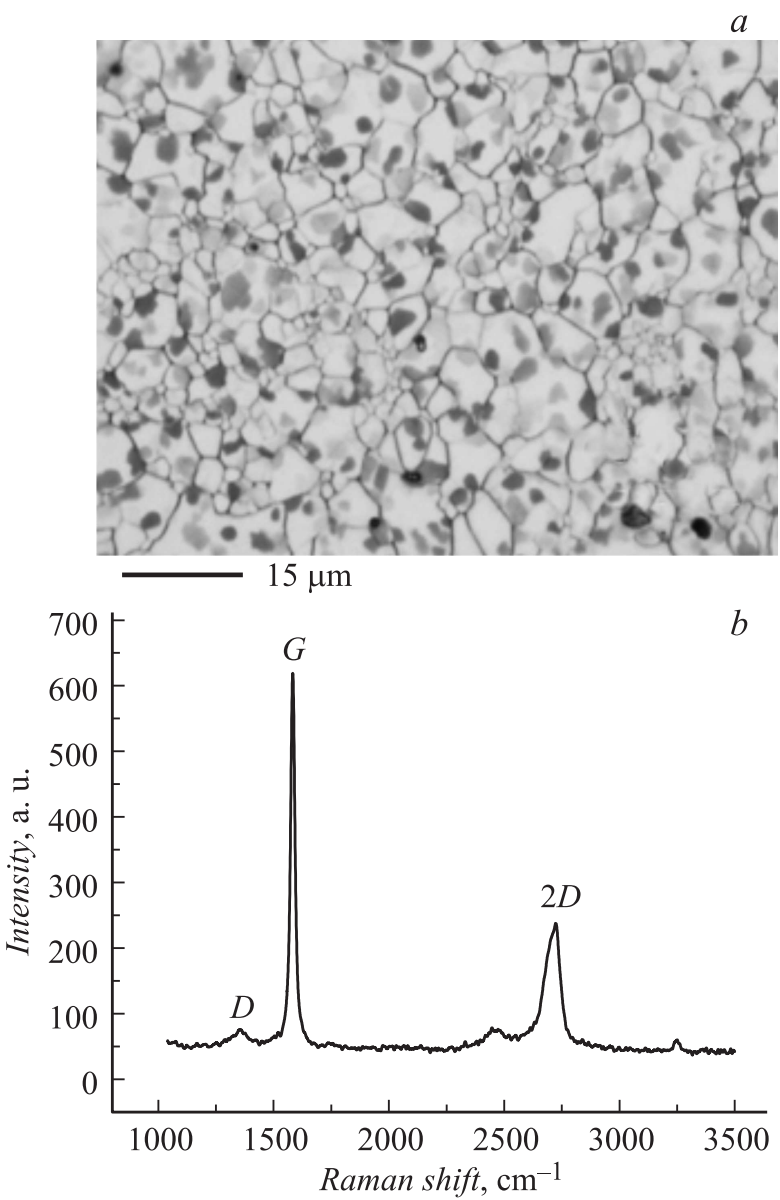

Pис. 2. $a-$ оптическое изображение поверхности пленки никеля после отжига при $960^{\circ} \mathrm{C}, b-$ спектр комбинационного рассеяния с темных фрагментов оптического изображения.

шении толщины адсорбированного слоя метана за счет распыления и испарения под воздействием ионного пучка.

После облучения ионами неона образцы отжигались в вакууме в течение $1 \mathrm{~min}$ при температурах 860, 900 и $960^{\circ} \mathrm{C}$. Оптическое 
изображение пленки никеля после отжига при $960^{\circ} \mathrm{C}$ (доза ионов неона $5 \cdot 10^{14} \mathrm{~cm}^{-2}$ ) приведено на рис. 2, $a$. Четко видны границы зерен и темные фрагменты, в основном примыкающие к границам зерен. Размер темных фрагментов колеблется в диапазоне $1-5 \mu \mathrm{m}$. На образцах, отожженных при более низких температурах, количество темных фрагментов и их размер уменьшаются с уменьшением температуры. Характеризация поверхности никелевой пленки после отжига проводилась методом рамановской спектроскопии на микроскопе SENTERA фирмы Broker с длиной волны возбуждающего лазера $532 \mathrm{~nm}$. Спектры комбинационного рассеяния с пленки никеля показывают, что темные фрагменты представляют собой многослойный графен. На рис. 2, $b$ приведен типичный спектр, снятый с темных фрагментов. Четко виден узкий (полуширина на полувысоте $22 \mathrm{~cm}^{-1}$ ) пик $G$, что говорит об упорядоченной гексагональной структуре расположения атомов углерода. Слабый пик $D$ свидетельствует о незначительном количестве дефектов. По форме, ширине и расположению пика $2 D$ можно судить о количестве слоев графена. Пик $2 D$ может быть разложен на три пика (лоренциана), что говорит о наличии как минимум 4 слоев графена.

Полученные результаты практически совпадают с результатами синтеза графена на поверхности поликристаллического никеля методом обычной высокоэнергетической имплантации ионов углерода [1-3]. Пленки графена получаются не сплошными, а области многослойного графена группируются возле границ зерен никелевой пленки. Отсюда можно сделать вывод, что процесс синтеза графена на поликристаллическом никеле определяется не способом и количеством внедренного углерода, а морфологией поверхности никелевой пленки. Наблюдается преимущественная диффузия углерода к поверхности по границам зерен во время отжига, что препятствует однородному росту монослойного графена по всей поверхности никелевой пленки. Из литературы известно, что получить однородные монослойные пленки графена можно только на монокристаллическом никеле с ориентацией (111) [3].

Отличительной особенностью метода имплантации атомов отдачи является высокая концентрация атомов углерода $\left(\sim 10^{22} \mathrm{~cm}^{-3}\right)$ в узком $(\sim 20 \mathrm{~nm})$ приповерхностном слое, что невозможно создать традиционной ионной имплантацией. Проведенные эксперименты показали, что метод имплантации атомов отдачи углерода может быть применен для синтеза пленок графена. Этот метод может представлять интерес для синтеза тонких пленок других химических соединений.

Письма в ЖТФ, 2017, том 43, вып. 12 


\section{Список литературы}

[1] Slaven Gara, William Hubbart, Golovchenko J.A. // Appl. Phys. Lett. 2010. V. 97. P. 183103 (3p.).

[2] Laurent Baraton, Zhanbing He, Chang Seok Lee et al. // Nanotechnology. 2011. V. 22. P. 085601 (5p.).

[3] Gutierres G., Le Normand F., Muller D. et al. // Carbon. 2014. V. 66. P. 1-10.

[4] Зиненко В.И., Агафонов Ю.А., Вяткин А.Ф., Пустовит А.Н. // Вестник ННГУ. Сер. Физ. тв. тела. 2005. В. 1 (8). С. 5-8.

[5] Вяткин А.Ф., Зиненко В.И., Агафонов Ю.А., Сарайкин В.В. Патент РФ. № 2523732. Приоритет от 30.01.2013.

[6] Kononenko O.V., Matveev V.N., Kasumov A.Yu. et al. // Vacuum. 1995. V. 46. N 7. P. 685-690. 